

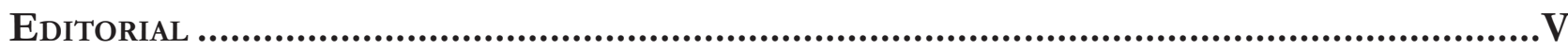

Carlos Ayres Britto, Lilian Rose Lemos Soares Nunes e Marcelo Dias Varella

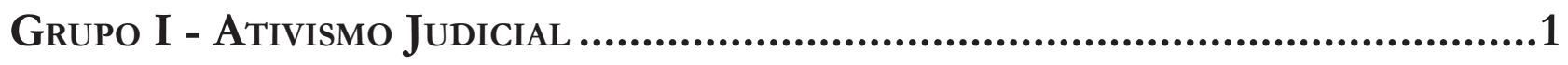

APONTAMENTOS PARA UM DEBATE SOBRE O ATIVISMO JUdiCIAL ................................................ 3 Inocêncio Mártires Coelho

A razão sem voto: o Supremo Tribunal Federal e o governo da maioria......................24 Luís Roberto Barroso

O PROBLEMA DO ATIVISMO JUDICIAL: UMA ANÁLISE DO CASO MS3326 ......................................52 Lenio Luiz Streck, Clarissa Tassinari e Adriano Obach Lepper

Do ativismo Judicial aO ATIVISMO CONSTITUCIONAL No Estado DE DIREITOS FUNDAMENTAIS..... 63 Christine Oliveira Peter

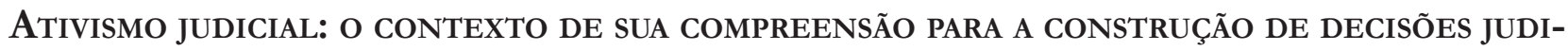
CIAIS RACIONAIS

Ciro di Benatti Galvão

HeRMENÊUTICA FILOSÓFICA E ATIVIDADE JUDICIAL PRAGMÁtICA: APROXIMAÇÕES 101 Humberto Fernandes de Moura

O PAPEL DOS PRECEDENTES PARA O CONTROLE DO ATIVISMO JUDICIAL NO CONTEXTO PÓS-POSITI-

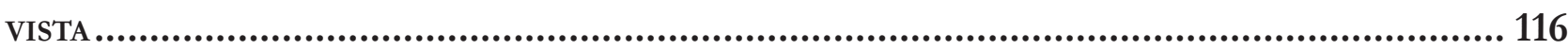
Lara Bonemer Azevedo da Rocha, Claudia Maria Barbosa

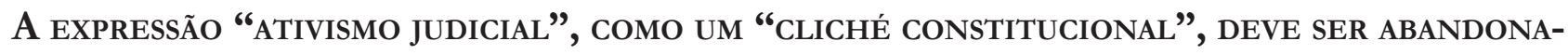
DA: UMA ANÁLISE CRÍTICA 135 Thiago Aguiar Pádua

A atuação do Supremo Tribunal Federal frente aos fenômenos da judicialização da POLÍTICA E DO ATIVISMO JUDICIAL 170

Mariana Oliveira de Sá e Vinícius Silva Bonfim 
Ativismo judicial e democracia: a ATUaÇão do STF E o EXercício da Cidadania no Brasil..191 Marilha Gabriela Reverendo Garau, Juliana Pessoa Mulatinho e Ana Beatriz Oliveira Reis

Grupo II - Ativismo Judicial e Políticas Públicas...................................207

Políticas Públicas E ATIVISMO JUdiCial: O DILEMa ENTRE EFETIVIDAde E LIMITES DE ATUAÇÃo............209 Ana Luisa Tarter Nunes, Nilton Carlos Coutinho e Rafael José Nadim de Lazari

Controle Judicial das Políticas Públicas: Perspectiva da hermenêutica filosófica e

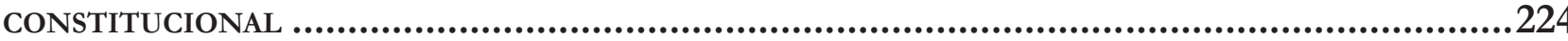

Selma Leite do Nascimento Sauerbronn de Souza

A atUAÇão do PODER JUdiciário NO ESTADO CONSTITUCIONAL EM FACE DO FENÔMENO DA JUDI-

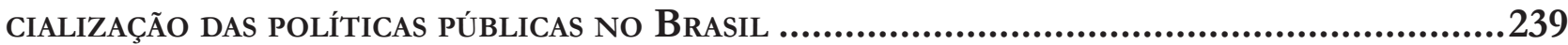

Sílvio Dagoberto Orsatto

Políticas PÚblicas E PROCESSO ELEITORAL: REFLEXÃo A PARTIR DA DEMOCRACIA COMO PROJETO POLÍTICO

Antonio Henrique Graciano Suxberger

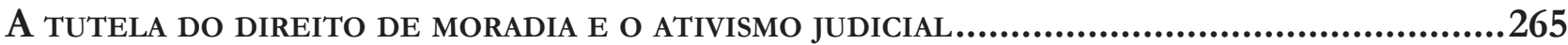

Paulo Afonso Cavichioli Carmona

Ativismo Judicial e Direito à Saúde: a judicialização das políticas públicas de saúde e os impactos da POStura ativista do Poder Judiciário.

Fernanda Tercetti Nunes Pereira

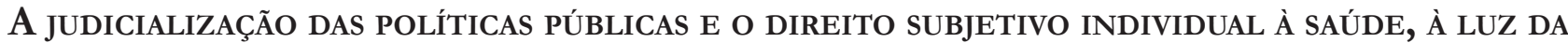
TEORIA DA JUSTIÇA DISTRIBUTIVA DE JoHN RAWLS

Urá Lobato Martins

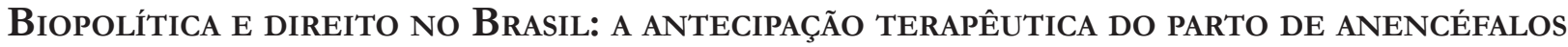
COMO PROCEDIMENTO DE NORMALIZAÇÃO DA VIDA

Paulo Germano Barrozo de Albuquerque e Ranulpho Rêgo Muraro

Ativismo judicial e judicialização da política da RelaÇão de Consumo: uma análise do CONTROLE JURISDicional dos CONTRATOS DE PLANOS DE SAÚDE PRIVAdo No ESTADo DE São

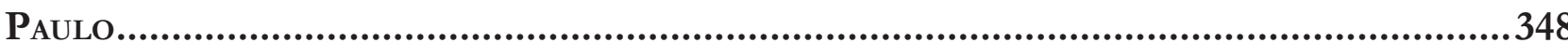
Renan Posella Mandarino e Marisa Helena D’Arbo Alves de Freitas 
A atuaÇão do Poder Judiciário na implementaÇão de políticas públicas: o caso da deMARCAÇÃO DOS TERRITÓRIOS QUILOMBOLAS ........................................................362 Larissa Ribeiro da Cruz Godoy

Políticas públicas e etNodesenVolvimento com ENFOQUe NA LEGISLAÇão INDigenista BRASILEIRA

Fábio Campelo Conrado de Holanda

Tentativas de contenção do ativismo judicial da Corte Interamericana de Direitos Humanos

Alice Rocha da Silva e Andrea de Quadros Dantas Echeverria

O desenvolvimento da Corte Interamericana de Direitos Humanos. .410 André Pires Gontijo

O ATivismo judicial da Corte Europeia de Justiça para alÉm da integração europeia...... 425 Giovana Maria Frisso

Grupo III - Ativismo Judicial e Democracia.....

Liberdade de Expressão e Democracia. Realidade intercambiante e necessidade de aprofundamento da Questão. Estudo comparativo. A jurisprudênCia do Supremo Tribunal Federal no Brasil- Adpf 130- e a Suprema Corte dos Estados Unidos da AmériCA.

Luís Inácio Lucena Adams

A germanística JuRídica e a metáfora do dedo EM Riste no CONTEXTO EXPLORATIVO das JUSTIFICATIVAS DA DOGMÁTICA DOS DIREITOS FUNDAMENTAIS

Arnaldo Sampaio de Moraes Godoy

Anarquismo Judicial e Segurança Jurídica Ivo Teixeira Gico Jr.

A (DES)hARMONIA ENTRE OS PODERES E O DiÁlOgo (IN)TENSO ENTRE DEMOCRACIA E REPÚBLI-

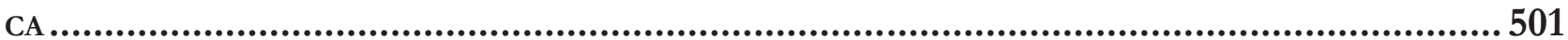

Aléssia de Barros Chevitarese

Promessas da modernidade e Ativismo Judicial. 519 Leonardo Zehuri Tovar

Por DENTRO DAS SUPREMAS CORTES: BASTIDORES, TELEVISIONAMENTO E A MAGIA DA TRIBUNA..... 538 Saul Tourinho Leal 
Direito Processual de grupos Sociais no Brasil: UMA VERsão REVISTA E ATUALIZADA DAS PRIMEIRAS LINHAS

Jefferson Carús Guedes

A OUTRA REALIDADE: O PANCONSTITUCIONALISMO NOS Isteites .

Thiago Aguiar de Pádua, Fábio Luiz Bragança Ferreira E Ana Carolina Borges de Oliveira

A resolução n. 23.389/2013 do Tribunal Superior Eleitoral E a tensão entre os podeRES CONSTITUÍDOS

Bernardo Silva de Seixas e Roberta Kelly Silva Souza

O RESTABELECIMENTO DO EXAME CRIMINOLÓGICO POR MEIO DA SÚMULA VINCULANTE $\mathrm{N}^{\circ}$ 26:

UMA MANIFESTAÇÃO DO ATIVISMO JUDICIAL .....................................................6 622

Flávia Ávila Penido e Jordânia Cláudia de Oliveira Gonçalves

Normas Editoriais .................................................................................6 637

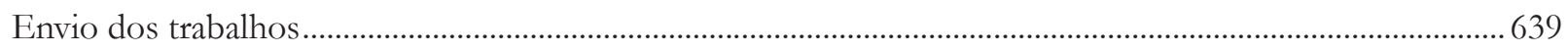




\section{Ativismo judicial: o contexto de sua compreensão para a construção de decisões judiciais racionais*}

\author{
Judicial activism: context of its \\ understanding for the construction of \\ rational judicial decisions
}

Ciro di Benatti Galvão**

\section{Resumo}

o presente artigo analisa o contemporâneo contexto sociojurídico e político de compreensão do ativismo judicial brasileiro com repercussão acerca do entendimento operativo da separação dos poderes. É sabido que a complexidade social e a previsão normativa de interesses e assuntos plurais têm feito com que as funções estatais sejam reanalisadas para que possam permanecer aptas a atender as suas funções preponderantes. Não seria diferente com a função jurisdicional do Estado. A partir da análise do citado contexto, percebe-se que uma renovação do princípio jurídico da Separação dos Poderes se mostra imprescindível para que a atividade precípua de solução de conflitos, com a consequente necessidade de preservação da pacificação social e alcance da noção de justiça, sejam obtidas. Renovando-se a sua compreensão, renova-se a legitimidade estatal junto à sociedade, quando da exigência por uma decisão judicial verdadeiramente racional. Para chegar-se a essa conclusão, a metodologia empregada baseou-se na coleta e análise crítica de argumentos de cunho doutrinário (muitas vezes, contrários entre si) suficientes para construir a linha pensamento adotada, favorável à adoção mais proativa (e, às vezes, criativa) da função jurisdicional do Estado, em especial, a da jurisdição constitucional com o objetivo de concretizar ou tutelar os valores e metas constitucionais do Estado.

Palavras-chave: Ativismo judicial. Separação dos poderes. Racionalidade judicial decisória.

* Recebido em 28/10/2014 Aprovado em 14/03/2015

** Bacharel em Direito pela Faculdade de Direito da Universidade Federal de Juiz de Fora (UFJF). Mestre em Ciências Jurídico-Políticas pela Faculdade de Direito da Universidade de Lisboa (FDUL) e em Direito do Estado pela Faculdade de Direito da Universidade de São Paulo (USP). Especialista em Direito Público. Professor de Direito Constitucional, de Teoria do Estado e de Direito Administrativo. Autor de artigos e de livros na área do direito. Advogado em Minas Gerais. E-mail: dibenatti@ yahoo.com.br

\section{Abstract}

This article examines the socio-legal context of understanding the Brazilian judicial activism. It is known that social complexity and the normative prediction of plural interests and subjects has forced State to recalculate its functions or powers so that they remain capable of well executing their predominant functions. It would not be different with the judicial function of the State. From the analysis of that context, it is noticed that a renewal of the principle of separation of powers is essential to the core activity of conflict resolution, with the consequent need to preserve and achieve social 
peace. Renewing the understanding of the judicial function, from the requirement for a truly rational judicial decision, the state legitimacy in society renews itself. To reach this conclusion, the methodology used was based on the analisis of critical and doctrinal arguments (often contrary of each other) sufficient to construct the line of thought adopted here, supporting the adoption of a proactive stance of the jurisdictional function of the State, in particular the constitutional jurisdiction in order to achieve or protect the constitutional values and goals of the State.

Keywords: Judicial activism. Separation of powers. Judicial rationality

\section{Conceituação, IMPORTÂNCIA E CONTEXTO SOCIOJURídico E Político de REALIZAÇÃo do ATI- VISMO JUDICIAL}

A temática da performance ou do comportamento do Poder Judiciário tem se tornado sedutora, em tempos atuais. Contrapondo-se à noção norte-americana de judicial self restraint, responsável pela adoção de um comportamento judicial de contenção autonomamente realizado, pelo qual há encorajamento dos membros do Poder Judiciário de autolimitar as suas fronteiras de atuação. O fenômeno do ativismo judicial ou judicial activism, envolvendo nova abordagem da função jurisdicional do Estado, tem levado a calorosos debates, condenando ou afirmando a sua importância, de acordo com o contexto em que se trabalha a questão.

Apesar de poder ser-lhe dirigida uma perspectiva analítica negativa ${ }^{1}$, a partir do levantamento de questões relativas à inexistência de legitimidade democrática da função jurisdicional (por assumir uma postura contramajoritária) e à eventual ofensa à noção técnica de separação dos poderes (em razão do pretenso comprometimento das funções típicas pertencentes ao demais poderes do Estado), culminando, na adoção de comportamento pretensamente impróprio e, até mesmo, abusivo do Judiciário, adotar-se-á uma análise positiva acerca de sua compreensão.

Embora trata-se de expressão cujo conteúdo semântico possa se mostrar plúrimo², compreende-se o ativismo judicial ${ }^{3}$, como sendo um comportamento proativo (e, por raras vezes, antecipador à função típica dos demais poderes constituídos do Estado), desempenhado pelo Judiciário (especialmente, em termos da jurisdição constitucional), mediante procedimento interpretativo-constitucional, com a justificativa de suprir ou corrigir deficiências ou insuficiências posturais das demais funções estatais (legislativa e administrativa), tendo o nítido escopo de melhor garantir, a partir de decisões judiciais, a correspondência do Estado com os valores albergados nas normas constitucionais ${ }^{4}$ (em especial, as normas-princípio), principalmente os ligados à proteção e ao aprimoramento dos direitos fundamentais e ao controle e/ou à racionalidade do exercício do poder estatal. ${ }^{5}$

1 Nas palavras de Randy Barnett: "judicial activism is used to criticize a judicial practice that is to be avoided by judges and opposed by the public". Cfr. BARNETT, Randy E. Constitutional Clichés. Capital University Law Review, v. 36, p. 495-496.

2 Cfr. YOUNG, Ernest A. Judicial activism and conservative politics. University of Colorado Law Review, v. 73, n. 4. p. 1139-1216, 2002.

3 Aproveita-se a oportunidade para correlacionar ao termo "ativismo judicial” o de "judicialização da política". Adota-se o pensamento de que a judicialização significa o encaminhamento ao Judiciário de questões político-sociais (que antes não tinham tanta ressonância decisória em termos judiciais em virtude da pretensa completude de tratamento pelas demais esferas de poder) para tomada de decisão final. Muitas vezes, o prévio amadurecimento deliberativo desses novos temas exercido no âmbito de decisão do Judiciário acaba refletindo, em certos casos, na necessidade de tomada de comportamentos novos, passíveis de serem enquadrados no exercício da função típica dos demais poderes, adotando-se não mais uma postura legislativa ou administrativa meramente negativa. Objetivamente, a judicialização, muitas vezes, está pressuposta ou inserida na postura ativista comportamental do Judiciário de maneira prévia a esta. Corroborando a análise que aqui se faz sobre a judicialização da política, cfr. HIRSCHL, Ran. O novo constitucionalismo e a judicialização da política pura no mundo. Revista de Direito Administrativo, n. 251, maio/ago. 2009. Na visão do autor tem-se que: "A judicialização da política agora inclui a transferência massiva, para os tribunais, de algumas das mais centrais e polêmicas controvérsias políticas em que uma democracia pode se envolver".

4 Em sentido próximo, BARROSO, Luís Roberto. O controle de constitucionalidade no direito brasileiro. São Paulo: Saraiva, 2011. p. 365.

5 Keenan D. Kmiec corrobora esta visão ao asseverar que "in other words, the Court is engaging in judicial activism when it 
A manutenção da ordem constitucional a partir, essencialmente, dos processos de constitucionalização do Direito torna a discussão do tema atrativa e a sua importância dirige-se, pois, à necessidade de se questionar a própria compreensão do sistema jurídico-constitucional a partir das espécies de normas que o compõem e das formas de sua aplicabilidade e de concretização pelos órgãos funcionais básicos do Estado.

Sabendo-se que a composição do ordenamento jurídico se faz por meio de normas-regra e de normas-princípio ${ }^{6}$, basilar se mostra o argumento de que o comportamento ativista da função jurisdicional mostra-se em afinidade com a constatação de que nem todas as questões fáticas que se tornam problemas para o Direito possuem, aprioristicamente, solução regrada previamente.

Crê-se que, se uma postura de autocontenção extrema é adotada, fatalmente predispõe-se a dizer o direito somente a partir de normas detentoras de certo grau de concretude prévia, apta a se enquadrar ao problema, na expectativa de evitar o comprometimento do sistema jurídico como se somente assim ele fosse constituído e compreendido.

Mas o direito não é conhecido, apenas, pelo que está posto ou positivado. Muitas vezes, a norma de decisão far-se-á mediante aplicação de dispositivos normativos, que passam a obter concretude a partir da análise do contexto que envolve o problema carecedor de solução jurídica, mediante a intervenção de intérpretes devidamente autorizados pelo próprio texto constitucional. É sabido que o ordenamento jurídico caracteriza-se não apenas por dispositivos normativos previamente prontos para serem aplicados, mas também, por conceitos normativos mais genéricos, fluidos e com maior capacidade de adaptação contextual, a exemplo dos princípios jurídicos (inclusive, alguns são subentendidos, diga-se de passagem, a exemplo da proporcionalidade, decorrente da interpretação adequada do art. $5^{\circ}$, LIV, da CF/88). Assim, em muitos casos, a adoção de uma postura jurisdicional menos autocontida revela-se mais indicada e, talvez, mais exitosa, de acordo com a complexidade apresentada pelo problema ao Poder Judiciário, justamente para dar concretude a normas de caráter constitucional mais genérico ou fluido, igualmente detentoras de importância e, portanto, carecedoras de efetividade prática.

A defesa da coerência normativa do ordenamento jurídico-constitucional — não importando quais as espécies normativas que o compõem - é (e, continuará sendo) uma necessidade atual, vinculada à preservação da ideia de unidade e harmonia jurídica, principalmente em termos constitucionais. Infelizmente, no entanto, percebe-se que há certa dificuldade na efetivação de muitas normas constitucionais pela atuação dos poderes Legislativo e Executivo, que tem a lei em sentido estrito ou como objetivo de seu atuação ou como base para a sua atuação. Especificamente em relação ao Legislativo, verifica-se a persistência de lacunas normativas provenientes da inércia regulamentadora a partir de decisões legislativas ou de sua má elaboração (especificamente, em termos de conteúdo), comprometendo situações sociais que se tornam conflituosas e que acabam sendo levadas à análise do Judiciário, exigindo-lhes uma definição em termos decisórios. Já em relação à atuação administrativa, tem-se, muitas vezes, a inércia de atuação camuflada na noção de discricionariedade administrativa ou mérito administrativo, refletido principalmente na adoção de políticas públicas em diversos setores.

Dessa maneira, sabendo-se que não cabe aos juízes eximir-se (princípio do non liquet) de decidir em razão de inexistência de norma posta regulamentadora ou da existência de certa antinomia, observa-se que a atividade interpretativa, na qual argumentos principiológicos possam ser realmente aproveitados, ganhando utilidade jurídica prática para a solução final, reforça a predisposição em se defender uma postura mais proativa dos órgãos judiciais ${ }^{7}$, dentro, obviamente, de parâmetros racionais em termos de decisão. Nesses termos,

reaches beyond the clear mandates of the Constitution to restrict the handiwork of the other government branches". Cfr. KMIEC, Keenan D. The Origin and Current Meanings of Judicial Activism. California Law Review, v. 92, issue 5, p. 1464-1465, 2004.

6 Cfr. ALEXY, Robert. Teoria dos direito fundamentais. Tradução de Virgílio Afonso da Silva. São Paulo: Malheiros, 2008. p. 87. BARROSO, Luís Roberto. O novo direito constitucional brasileiro: contribuições para a construção teórica e prática da jurisdição constitucional no Brasil. Belo Horizonte: Fórum, 2013. p. 147.

7 No mesmo sentido, Cfr. SANTAROSA, Humberto. Jurisdição Criativa e a motivação das decisões judiciais como seu aspecto legitimador. In: FUX, Luiz (coord.). Processo Constitucional. Rio de Janeiro: Forense, 2013. p. 567. 
aponta-se, como parâmetro especial a esse perfil comportamental do Judiciário, a motivação argumentativa, que continuamente merece guarida em termos jurídico, ganhando, enfim, ressonância e considerável grau de importância em todo comportamento decisório.

Tradicionalmente concebida como elemento garantidor do controle da atividade decisória, por facilitar a sua correspondência e adequação à noção de legalidade (juridicidade), passa-se, atualmente, a concebê-la e/ ou compreendê-la, em todos os âmbitos decisórios estatais, como uma exigência de racionalidade jurídica de cunho objetivo, conformadora de um adequado iter ou processo de fixação dos entendimentos e razões que serão expostos na decisão final a ser tomada. Explica-se: ao mesmo tempo, a exposição de razões e argumentos serve para facilitar ou potencializar a fiscalização da decisão final (a posteriori) mas, igualmente, na condição de dever jurídico fundamental objetivo, significa a preocupação própria de quem decide em fazê-lo em conformidade com noções fundamentais do ordenamento jurídico, garantindo-lhe pertinência, coerência e racionalidade, evitando-se as chances das decisões serem atacadas, invalidadas ou questionadas, alcançando, também, maior grau de legitimidade (é o que se denomina de vocaşão jurídico-racional preventiva).8

No caso específico do comportamento de não autocontenção do poder judiciário, o dever jurídico de motivação de base jurídico-argumentativa revela-se elemento essencial, apto a justificar eventual decisão que, possivelmente, seja objeto de contestação por, pretensamente, contrariar a noção de separação de poderes ou por se revelar como decisão contramajoritária, pois, atualmente, impera a busca por funcionalidade operativa no exercício das funções estatais clássicas, de maneira que as decisões dos poderes constituídos devem apresentar-se verdadeiramente úteis ao propósito para qual as funções são exercidas (conforme se verá adiante).

Classicamente, em relação à função judicial, diz-se que ela está condicionada a extinguir litígios, (justa composição das lides ${ }^{9}$ ) e/ou combater ilegalidades, aplicando-se concretamente a vontade do direto objetivo vigente, com a finalidade última e geral de obter pacificação, ordenação e organização sociais.

Contudo, a partir da assunção dos Estados tipicamente Constitucionais, centrando-se o ordenamento nas disposições normativas do texto constitucional, especificamente em sua força normativa e em sua necessidade permanente de efetivar-se, volta-se o olhar crítico às pretensões funcionais desempenhadas pelo Poder Judiciário. Acrescente-se a isso a análise da própria evolutção do Estado, com nítido e exponencial crescimento da complexidade dos assuntos levados à resolução por ele, constatando-se que a decisão final tende a não ser tão diretamente buscada em dispositivos legais em sentido estrito e previamente existentes, simplesmente para apaziguar situações conflituosas.

A utilidade e a operacionalidade das decisões judiciais passam a se apresentar mediante o recurso a argumentos de ordem valorativa contidos em normas principiológicas (especialmente, em princípios constitucionais), relativizando, pretensamente, e, de antemão a harmonia (originalmente concebida) dos poderes, implicando, no entanto, e, eventualmente, uma significativa e indicada releitura da postura do Judiciário ${ }^{10}$, visto que ele tende a ser mostrar como um dos principais atores de realização das intenções constitucionais e resguardo da unidade da normatividade constitucional.

Nesses termos, a argumentação motivada das decisões judiciais, baseada na utilização sistêmica das normas do ordenamento jurídico, a partir, obviamente, das normas constitucionais e que, eventualmente, possam indicar uma falsa ideia de invasão ou contrariedade às normas de competência legais dos demais poderes constituídos, passa a auxiliar o Poder Judiciário na obtenção de um esforço funcional mais complexo, revelador de um aprimoramento apto e crucial à potencialização da cumprimento da sua própria função típica e de atribuição de legitimidade ao próprio Estado.

8 Cfr. GALVÃO, Ciro di Benatti. O dever jurídico de motivação administrativa: parâmetro objetivo para a racionalidade decisória dos atos administrativos restritivos de direito. Rio de Janeiro: Lumen Juris, 2013. p. 105 e ss.

9 Cfr. MEDINA, Paulo Roberto de Gouvêa. Teoria geral do processo. Belo Horizonte: Del Rey, 2012. p. 97.

10 Nesse sentido, precisas se mostram as palavras de Luiz Guilherme Marinoni para quem: "A transformação da concepção de direito fez surgir um positivismo crítico, que passou a desenvolver teorias destinadas a dar ao juiz a real possibilidade de afirmar o conteúdo da lei comprometido com a Constituição". Cfr. MARINONI, Luiz Guilherme. A jurisdição no Estado constitucional. Disponível em: <http://www.marinoni.adv.br/artigos.php>. Acesso em: 06 out. 2014. 
A variação de posicionamento (pró judicial activism ou pró judicial self restraint) também está condicionada à análise do contexto sociopolítico em que se exerce a função jurisdicional do Estado.

Variando o momento de evolução estatal, as mudanças sofridas pelo Estado refletem na atuação ou no comportamento de seus poderes constituídos. Ou seja, toda manifestação de poder estatal está condicionada ou, ao menos, significativamente, influenciada pelo contexto de incidência do Estado e do Direito que o regulamenta. Não há porque contrapor-se a essa afirmação.

Relativamente ao Poder Judiciário e, portanto, ao exercício da função jurisdicional do Estado, percebe-se que a superação da fase tipicamente liberal e a inserção, ainda, no contexto social tem feito com que constatemos a necessidade enfrentada por ele em lidar com as novas e complexas questões que lhe são direcionadas, a exemplo das demandas judiciais vinculadas à questão do direto fundamental à vida e à saúde, meio ambiente, bem como demandas referentes à liberdade em suas mais diversas perspectivas (liberdade religiosa, liberdade sexual, liberdade de consciência, liberdade de expressão e de pensamento etc.), cobrando-lhe comportamentos afirmativos, positivos.

Verifica-se que a chamada crise do contexto estatal vem forçando a ruptura de paradigma da jurisdição como um todo, em especial da jurisdição constitucional, que passa a depender de uma postura mais operativa e criativa em sua função típica, passando a depender de um perfil que requer-lhe comprometimento para a realização e/ou concretização de uma suposta ordem de valores presentes nas determinações legais, em especial, nas determinações de cunho constitucional, mediante correções às funções próprias exercidas pelas demais manifestações de poder do Estado, especialmente, pelo Poder Legislativo. Não se tolera, ou melhor, não se coaduna mais com um perfil do Poder Judiciário conivente com os silêncios ou omissões das demais funções estatais, geralmente rendidas por questões meramente políticas e, muitas vezes, partidárias, comprometedoras de realização de direitos fundamentais, inclusive de minorias em termos de representação política.

Faz-se, portanto, e, na visão de Marcelo Cattoni, uma conexão entre o "Direito e a realização do que a nação, corporificada na figura estatal, entende como bem-comum"11, ou seja: "a jurisdição constitucional assumirá o lugar de um poder constituinte permanente de desenvolvimento de valores pressupostos à Constituição" 12 , servindo de figura intermédia para o alcance e/ou aperfeiçoamento dos valores constitucionais presentes tanto nos direitos fundamentais, quanto nas instituições democráticas, constatada a impossibilidade do processo de "autorrealização da identidade cívica" ${ }^{13}$ da própria sociedade.

Ainda dentro do contexto sócio-político de desenvolvimento do pensamento ativista (em termos judiciais), pode ser afirmado que a correspondente e nova postura do Judiciário (em específico, da jurisdição constitucional) se justifica, ainda, a partir de outra significativa situação constatável: a famigerada crise da representatividade política, em especial a do Legislativo, derivada, em sua essência, da inoperância, incompletude e da falta de apreço à qualidade legislativa.

Anteriormente, vigorava a certeza e a confiança real de que os entes legislativos pudessem prever, mediante normas legislativas próprias, as situações e os comportamentos sociais, de maneira que eventuais incompletudes poderiam ser sanadas pelos métodos tradicionais de interpretação jurídica. $\mathrm{O}$ dogma da completude legislativa imperava. O Direito (e, portanto, a noção de justiça) era compreendido e se perfazia, apenas, a partir dessa ótica, de maneira que a função judicial baseava-se, predominantemente, na busca de enquadramento perfeito e lógico entre enunciado normativo e o seu contexto de aplicação prática, ou seja: bastava-lhe uma atuação mecanicista.

A aceleração das mudanças sociais ${ }^{14}$ e a complexidade do mundo da vida passam a forçar a crucial alternância de perspectiva analítica acerca do papel do Poder Legislativo e de sua, até então, absoluta aptidão de

11 OLIVEIRA, Marcelo Andrade Cattoni de. Teoria da Constituição. Belo Horizonte: Initia Via, 2012. p. 203.

12 OLIVEIRA, Marcelo Andrade Cattoni de. Teoria da Constituição. Belo Horizonte: Initia Via, 2012. p. 204.

13 OLIVEIRA, Marcelo Andrade Cattoni de. Teoria da Constituição. Belo Horizonte: Initia Via, 2012. p. 204.

14 PELEJA JÚNIOR, Antônio Veloso. As sentenças aditivas na jurisdição constitucional. In: FUX, Luiz (coord.). Processo Constitucional. Rio de Janeiro: Forense, 2013. p. 175. 
regulamentação social. Soma-se a isso a constatação de significativas falhas no processo legislativo, especificamente mediante a constatação de que, nem sempre, a orientação jurídico-normativa do Poder Legislativo, no exercício de sua função legiferante, está em sintonia com a realização da "vontade de constituição"15, tão bem trabalhada por Konrad Hesse, sucumbindo a verdadeiras vontades ou perfis parciais de poder, próximas da noção de dominação de fatores reais de poder socialmente incidentes e comprometedores do projeto denominado, aqui, de obtenção de uma Constituição inclusiva on agregadora.

A má qualidade dos textos legislativos produzidas pelos Parlamentos correspondentes e a recusa consciente e, até mesmo, a transferência de responsabilidade pela deliberação juridicamente inclusiva e tolerante acerca de muitas questões controvertidas e pungentes, tem levado a que, a posteriori, haja intervenção subsidiária, mas necessária, dos demais poderes constituídos, especialmente, do Judiciário, apta a dar-lhe contornos realmente racionais em termos jurídico-constitucional. Dessa forma, compartilha-se das observações feitas por Lênio Streck ${ }^{16}$ acerca da atuação da jurisdição constitucional, dispondo que haja de sua parte

[...] uma nova inserção no âmbito das relações dos poderes de Estado, transcendendo as funções de cheks and balances, mediante uma atuação que leve em conta a perspectiva de que os valores constitucionais têm precedência mesmo contra textos legislativos produzidos por maiorias parlamentares.

É o que tem sido denominado de postura contramajoritária, principalmente valendo-se do argumento de proteção e/ou aprimoramento de direitos fundamentais afetados, seja pela inexistência de textos legislativos, seja pela sua feitura deficitária ou omissa.

Reconhece-se que há, de fato, uma crise na função legislativa estatal ou crise de representatividade legislativa (principalmente, se levarmos em consideração o nível de despreparo técnico-funcional dos componentes ou, o que é pior, a apatia pessoal em buscar o know-how necessário a ser aplicado à atividade legislativa) e que carece de superação urgente, mas que somente vai se dar a partir do comprometimento do órgão em se transformar, de fato, numa arena ou lócus de deliberação séria e comprometida das necessidades sociais, amparadas, obviamente, em valores materialmente constitucionais, realizando verdadeira filtragem, pois nem tudo que é socialmente desejável será juridicamente viável de incidir.

Nesse sentido, a alteração ou o aperfeiçoamento do Legislativo como lócus deliberativo-decisório urge e se mostra salutar. Mas, infelizmente, a sua colonização inadequada força e/ou concretiza a necessidade de ordenação social juridicamente pertinente por meios alternativos (juridicamente amadurecidos e pensados), pois o mote fundamental de alcançar, manter e aprimorar a ordenação social persiste desde a concepção técnica de Estado, datada do século XVI, com a subsequente necessidade de vincular a ideia de ordenação social com os ideias do constitucionalismo.

\section{A NOÇÃo OPERACIONAL DA SEPARAÇÃo dOS PODERES ESTATAIS E SUA APLICAÇÃo À JURISDIÇÃO CONSTITUCIONAL}

Quando um dos atores responsáveis pela representação dos poderes constituídos do Estado falha deliberadamente ou não, poderia outro substituir-lhe ou corrigir a sua eventual falha, imprecisão ou omissão para efetivar o conteúdo substancial do texto constitucional? E, mais: principalmente, no que se refere às temáticas relativas a direitos fundamentais e à necessidade de controle e racionalização do poder estatal, tal comportamento mostra-se viável em Estados de Direito? Haveria, a partir da normatividade constitucional, uma justificativa argumentativa que pudesse defender a resposta positiva dos questionamentos acima?

15 HESSE, Konrad. A força normativa da Constituição. Tradução de Gilmar Ferreira Mendes. Porto Alegre: S. A. Fabris, 2002.

16 STRECK, Lênio Luiz. Jurisdição Constitucional e Hermenêutica: perspectivas e possibilidades de concretização dos direitos fundamentais sociais no Brasil. Novos Estudos Jurídicos, v. 8, n. 2, p. 257-301, 2003. p. 281. 
O enfretamento das colocações acima pressupõe a) a tentativa de reconfiguração do princípio jurídico da Separação dos Poderes, dando-lhe contornos mais atualizados a fim de que possa corresponder aos ideais da evolução do constitucionalismo, principalmente, no que tange ao chamado constitucionalismo da efetividade; b) a concretização da característica de autocorreção constitucional, feita institucionalmente, com vistas ao aperfeiçoamento social e à garantia de valores constitucionais, conforme será visto.

A partir de certa perspectiva compreensiva, a Separação dos Poderes implica(va) a defesa do raciocínio de evitar-se concentração e abuso do poder estatal, retrocedendo a um contexto arbitrário e contrário à proteção ou garantia da esfera jurídico-subjetiva do indivíduo diante do Estado. Priorizou-se a necessidade de distribuir as funções estatais a entes ou órgãos diferentes, autônomos e independentes entre si, havendo controle mínimo e recíproco, impedindo-se, no entanto, a descaracterização das competências e funções típicas desempenhadas por cada um. Trata-se da dimensão garantística ou negativa de tal princípio estruturante do Estado de Direito, amparado no pensamento liberal de John Locke, aprimorado por Montesquieu, como tradicionalmente se analisa a temática. ${ }^{17}$

Importante ser salientado, no entanto, que há certa ampliação entre os "espaços de interseção e fricção" entre o Judiciário e os demais poderes constituídos, potencializando, conforme observa Luís Roberto Barroso, a necessidade de demarcação do "âmbito de atuação legítima" de cada um, atentando-se, no entanto, para o fato de que as eventuais fronteiras demarcatórias não devem se mostrar fixas ou extremamente rígidas, devido à "existência dinâmica e pendular" das citadas interações. ${ }^{18}$

É nesse cenário que se redesenha a noção jurídica da separação dos poderes, levando-se em consideração o fato de que, no que diz respeito à jurisdição constitucional, a sua vocação imediata está na tutela e/ou no aperfeiçoamento dos objetivos primários do constitucionalismo moderno e contemporâneo, evidenciando-se, por óbvio e, devido a sua importância para o desenvolvimento do indivíduo (em suas mais diferentes manifestações), os direitos fundamentais e os valores constitucionais albergados por eles, muitas vezes.

Para se alcançar tal desiderato, a separação dos poderes passa a admitir uma perspectiva positiva ou operativa, relativa à necessidade de que seja atribuído um aumento da capacidade de atuação racional ${ }^{19}$ (para alguns, até criativo ${ }^{20}$ ) dos órgãos executores das funções estatais, de maneira que potencializem suas funções típicas, tornando-se verdadeiramente úteis à realidade estatal e ao elemento subjetivo de composição do Estado, ou seja, aos cidadãos em sua dimensão individual e/ou coletiva.

Pretende-se, com essa visão, ordenar racionalmente ${ }^{21}$ o contexto social e as problemáticas dele advindas e, a partir da noção jurídica de vontade de constituição22, tornar as decisões dos órgãos estatais funcionalmente

17 No mesmo sentido, cfr. NOVAIS, Jorge Reis. Separação de poderes e limites da competência legislativa da Assembleia da República. Lisboa: Lex, 1997. p. 25 e ss. PIÇARRA, Nuno. A Separação dos Poderes como doutrina e princípio constitucional: um contributo ara o estudo das suas origens e evolução. Coimbra: Coimbra, 1989. p. 13. CANOTILHO, J. J. Gomes. Direito constitucional e teoria da constituição. 7. ed. Coimbra: Coimbra, 2003. p. 250. STRECK, Lênio Luiz; OLIVEIRA, Fábio de. Comentário ao art. 2. In: CANOTILHO, J. J. Gomes et al. (Coord.). Comentários à Constituição do Brasil. São Paulo: Saraiva; Almedina, 2013. p. 142.

18 BARROSO, Luís Roberto. Direito constitucional contemporâneo. São Paulo: Saraiva, 2012. p. 383 -386.

19 Sobre este ponto, cfr. NOVAIS, Jorge Reis. Separação de poderes e limites da competência legislativa da Assembleia da República. Lisboa: Lex, 1997. p. 25-26; PIÇARRA, Nuno. A Separação dos Poderes como doutrina e princípio constitucional: um contributo ara o estudo das suas origens e evolução. Coimbra: Coimbra, 1989. p. 262; NOVAIS, Jorge Reis. Os princípios constitucionais estruturantes da República Portuguesa. Coimbra: Coimbra, 2011. p. 34.

20 Sobre uma criatividade pautada na inexistência e inadmissibilidade de argumentos meramente voluntaristas do intérpreteJudiciário, cfr. STRECK, Lênio Luiz; OLIVEIRA, Fábio de. Comentário ao art. 2º. In: CANOTILHO, J. J. Gomes et al. (Coord.). Comentários à Constituição do Brasil. São Paulo: Saraiva; Almedina, 2013. p. 147.

21 Neste sentido, cfr. SCHMIDT-ASSMANN, Eberhard. La teoria general del derecho administrativo como sistema: objeto y fundamentos de la construcción sistemática. Madri: INAP, 2003. p. 193. Na literalidade do pensamento do autor tem-se que: "en definitiva, la finalidade fundamental de la separación de poderes, a saber: generar racionalidade através de estructuras diferenciadas, no se halla hoy en día superada, ni fáctica ni juridicamente".

22 Adota-se com esta expressão a concepção fornecida por Konrad Hesse em sua obra ao referir-se à ela como a necessidade dos atores da realidade social (e, a nosso ver as instituições jurídicas) se conformarem de acordo com a normatividade constitucional e, mais: se predisporem a atribuir e concretizar as ordenações provenientes do texto constitucional. Cfr. HESSE, Konrad. A força normativa da Constituição. Tradução de Gilmar Ferreira Mendes. Porto Alegre: S. A. Fabris, 2002. p. 8. 
adequadas e substancialmente justas e coerentes, lembrando, sempre, que essa perspectiva positiva requer, para se justificar e evitar decisionismos, a noção de responsiveness e accountability (exigência de capacidade e de responsabilidade funcional sujeita a controle, digamos assim).

Afinal, conforme prudentemente adverte Lênio Streck, "a decisão adequada constitucionalmente exsurgirá da reconstrução do Direito, com efetivo respeito à integridade e à coerência"23, não devendo ser o reflexo de uma "opção política por valores" (grifo nosso), cabendo aos juízes construírem seus argumentos de forma integrada ao conjunto do direito, recomendação objetiva que limita qualquer subjetivismo eventualmente passível de manifestação. ${ }^{24}$

Obedecida essa exigência de adequação da decisão judicial à integridade e coerência da ordem jurídico-constitucional (manifestada, obviamente, conforme já exposto, pela exigência de motivação argumentativa-normativa) afirma-se que a atualização do perfil que o Poder Judiciário pode passar a adotar poderá albergar tanto a necessidade de concretização e efetividade constitucional, quanto de segurança jurídica e proteção social contra subjetivismos.

Tomemos como embasamento jurisprudencial apto a reforçar o perfil ativista do Judiciário, a partir da perspectiva operativa apresentada acerca da Separação dos Poderes a decisão emanada pelo STF acerca da análise da ADI 4277/DF, cuja relatoria coube ao Ministro Ayres Britto, julgada em 05 de maio de 2011, bem como da ADPF 132.

As referidas ações processuais objetivas se referiam à discussão e análise da pertinência constitucional da temática alusiva à proteção jurídico-constitucional das uniões estáveis entre pessoas de mesmo sexo a fim de lhes fossem garantidos os mesmos direitos que a legislação civil infraconstitucional garante às parcerias interpessoais heterossexuais, de maneira a realizar a interpretação adequada e coerente do Código Civil (especificamente o art. 1723) com o texto constitucional, com consequente extração da norma de decisão pertinente a efetivar as pretensões de inclusão e de repúdio à desigualdade e de desrespeito à dignidade humana, na condição de capacidade de autodeterminação individual e de reciprocidade de tratamento respeitoso, ensejando a possibilidade automática de que haja, caso fosse (e seja) de interesse pessoal, a sua conversão em casamento, nos moldes do que determina o $\$ 3^{\circ}$ do artigo 226 do texto constitucional.

Institucionalizou-se, portanto, não somente a união estável homoafetiva, mas, também, a viabilidade da ocorrência do casamento civil entre pessoas do mesmo sexo, com todos as implicações jurídicas advindas desse instituto. Percebe-se, claramente, que, no caso em tela, prescindiu-se de deliberação sobre a matéria em âmbito interno da arena político-parlamentar, que, possivelmente, manifestaria contrariedade à questão devido a sua composição, que, pela heterogeneidade, abarca setores conservadores, nitidamente em razão de considerável parcela da bancada evangélica.

A jurisdição constitucional exercida pelo STF atuou, portanto, a partir de procedimento interpretativo baseado em valores constitucionais presentes em dispositivos expressos, como lócus especializado de deliberação e de decisão acerca de um assunto que, pelo viés nitidamente sociopolítico e pela resistência ou resquícios de sexíssimos e preconceitos, certamente não encontraria regulamentação jurídica adequada em termos de legislação infraconstitucional. Pretendeu-se inovar, instituindo-se, mediante decisão judicial, não apenas a união estável entre pessoas do mesmo sexo, mas, também, o casamento civil por consequência lógica, corrigindo-se não apenas a falha do constituinte originário, mas a omissão ou mora do legislador infraconstitucional civil no que tange à regulamentação dessa matéria, tornando o texto constitucional verdadeiramente inclusivo nesse aspecto, atribuindo-lhe efetividade no que diz respeito aos enunciados normativos do art. $3^{\circ}$, III e do art. $5^{\circ}$, caput, por exemplo.

23 STRECK, Lênio Luiz. Hermenêutica e princípios da interpretação constitucional. In: CANOTILHO. J. J. Gomes et al. (Coord.). Comentários à Constituição do Brasil. São Paulo: Saraiva; Almedina, 2013. p. 82.

24 STRECK, Lênio Luiz. Hermenêutica e princípios da interpretação constitucional. In: CANOTILHO. J. J. Gomes et al. (Coord.). Comentários à Constituição do Brasil. São Paulo: Saraiva; Almedina, 2013. p. 82-87. 
Perpetuar a sujeição da união civil homoafetiva a uma pretensa regulamentação infraconstitucional a fim de que pudesse-lhe resguardar ou atribuir direitos próprios desse instituto, já verificados e atribuídos às uniões heterossexuais, representaria a perpetuação de uma omissão jurídico-constitucional reveladora de opressão, desconsideração e desrespeito. Admitir que o Legislativo viesse a regulamentar adequadamente essa questão seria sujeitar os parceiros homossexuais a uma decisão majoritária de inquestionável dúvida existencial diante da composição parlamentar em termos representativos. Optou-se pela adoção de postura contramajoritária, com nítido viés inclusivo e dignificante.

Decisão também emblemática e significativa, reforçando o perfil ativista (e, com embasamento argumentativo plausível, diga-se de passagem), foi a preferida em sede de julgamento do Mandado de Injunção (MI) $\mathrm{n}^{\circ} 712 / \mathrm{PA}$ cuja relatoria coube ao Ministro Eros Grau. Diferentemente do entendimento adotado em pretérita ação sobre a mesma temática (MI no 20), adotou-se o posicionamento de repreender a mora legislativa referente à regulamentação do direito de greve dos servidores públicos, determinando-se que, ao contrário de apenas comunicar o Congresso de sua mora legislativa, determinasse-se que a lei geral sobre o direito de greve (Lei n $\left.{ }^{\circ} 7.783 / 89\right)$ incidisse amplamente para os casos análogos no serviço público até que, finalmente, o órgão legislativo cumprisse com a sua função precípua de regulamentação legislativa. Amparou-se no argumento de que estava se tratando de direito ou prerrogativa fundamental individual, consubstanciado no texto constitucional, no art. 37, VII. O interessante nesse processo estava no fato de que ação processual pretérita que versava sobre o mesmo assunto dispôs, em termos decisórios, de maneira autocontida no que se refere ao perfil do STF, ao estipular, apenas, que fosse dada ciência ao Legislativo acerca de sua mora legislativa. Transcorrido considerável lapso temporal, com o advento do $\mathrm{MI} \mathrm{n}^{\circ}$ 712/PA verificou-se a necessidade de se alterar o perfil comportamental em termos decisórios não contentando-se mais com a cientificação do órgão faltante, impondo-se medida decisiva que pudesse, realmente, efetivar a norma constitucional constante do art. 37 , II, carecedor de produção de efeitos jurídicos concretos e amplos. O perfil institucional, portanto, renovou-se em razão da tutela adequada de posições jurídio-subjetivas fundamentais em termos constitucionais.

\section{Conclusão}

"É grande a tentação de reconhecer o Judiciário como uma elite capaz de se desviar dos trechos demasiadamente embaraçados da estrada do processo democrático. Tratar-se-ia, contudo, de desviação só aparentemente provisória; em realidade, seria ela a entrada de uma via incapaz de se reunir à estrada principal, conduzindo inevitavelmente, por mais longo e tortuoso que seja o caminho, ao estado totalitário." Essa frase dita por Lord Devlin e reproduzida por Mauro Cappeletti, em sua obra "Juízes Legisladores", serve-nos de apoio para reafirmar alguns pontos cruciais das intenções dadas à questão do ativismo judicial neste artigo.

Diferentemente do que correntemente se apregoa quando do tratamento da temática, jamais, em Estados de Direito, defender-se-á quaisquer manifestações totalitaristas, por se mostrarem, obviamente, contrárias aos ideais do desenvolvimento do Estado, pós contexto oitocentista. O que se pretende, mediante a realização de posturas ativistas, não é fragilizar ou comprometer o esquema organizatório-funcional do Estado, mas, antes, garantir-lhe legitimidade mediante a boa e coerente atuação das funções estatais, a partir da busca por utilidade nas decisões vinculadas à competência precípua de cada um de seus órgãos. Há que se ter condições de aperfeiçoar continuamente as funções precípuas de cada órgão estatal para que se possa ter verdadeiramente um cenário racional do próprio Estado.

À necessidade de defender a autonomia dos órgãos responsáveis pela realização do poder estatal em âmbito interno de maneira que desmandos ou ingerências abusivas sejam verificadas, soma-se, atualmente, a necessidade de aperfeiçoamento constante das maneiras de exercício de suas competências próprias, vinculadas, cada qual, à noção de aperfeiçoamento do próprio poder de conformação social do Estado. 
A garantia de uma organização estrutural racional do poder estatal, refletida no desempenho adequado e coerente das especialidades funcionais (competências) dos órgãos estatais para atender as múltiplas tarefas do Estado (e, para suprir a crise de representatividade política), garantindo-se ordenação social desejada, pressupõe não somente a não intervenção excessiva dos poderes constituídos entre si, mas o aumento da capacidade produtivo-funcional, buscada na possiblidade de atribuição de maior liberdade de atuação, mas baseada, obviamente, em critérios objetivos de comportamento decisório, a exemplo da motivação argumentativa, da noção de responsiveness e accountability em termos decisórios.

Se a Constituição deve criar mecanismos ou condições adequadas à obtenção da autorracionalidade e autoaperfeiçoamento da própria sociedade, segundo observado prudentemente por Gomes Canotilho ${ }^{25}$, não se mostra impertinente a defesa do ativismo como manifestação desse ideal constitucional por meio de comportamentos corretivos aos demais poderes constituídos, realizáveis a partir de processos interpretativos de base jurídico-argumentativa.

A partir disso, pode ser dito que o Poder Judiciário, hoje, passa a ser, também, um lócus adequado de decisão por deliberação, destituindo-se da exclusiva atividade mecânica de enquadramento lógico dos textos normativos às situações sociais controvertidas.

A ele deve ser garantido espaço de atuação e estruturação em que as suas decisões, a partir de métodos e princípios de interpretação constitucional, sejam autor responsavelmente deliberadas para que possa cumprir adequadamente com a realização de sua função precípua, que no caso específico, não é mais, apenas, resolver litígios, mas, verdadeiramente, posicionar a parcela do poder estatal manifestado por si de maneira a realizar a justiça constitucional, ou seja, obter decisões que reflitam o ideal valorativo que identifica o correspondente texto constitucional, garantindo-lhe efetividade real. A utilidade decisória que se espera encontrar em cada órgão funcional estatal, principalmente relativa ao aprimoramento da normatividade constitucional, depende dessa compreensão operativa, de maneira que comportamentos de autocontenção podem não concretizar a contento essa vocação de realização valorativo do texto constitucional.

\section{REFERÊNCIAS}

ALEXY, Robert. Teoria dos direito fundamentais. Tradução de Virgílio Afonso da Silva. São Paulo: Malheiros, 2008.

BARNETT, Randy E. Constitutional Clichés. Capital University Law Review, v. 36, p. 495-496.

BARROSO, Luís Roberto. Direito constitucional contemporâneo. São Paulo: Saraiva, 2012.

BARROSO, Luís Roberto. O controle de constitucionalidade no direito brasileiro. São Paulo: Saraiva, 2011.

BARROSO, Luís Roberto. O novo direito constitucional brasileiro: contribuições para a construção teórica e prática da jurisdição constitucional no Brasil. Belo Horizonte: Fórum, 2013.

BRASIL. Supremo Tribunal Federal. Acórdão no Mandado de Injunção n.20/DF. Relator: MELLO, Celso de. Publicado no DJ de 22-11-1996 p. 45690. Disponível em: < http://redir.stf.jus.br/paginadorpub/paginador.jsp?docTP=AC\&docID=81733>. Acesso em: 27 out. 2014.

BRASIL. Supremo Tribunal Federal. Acórdão no Mandado de Injunção n 712. Relator: Min. Eros Grau. Publicado no DJ de 25 -10-2007. Disponível em: <http://www.sbdp.org.br/arquivos/material/282_MI712_-_ Eros_Grau.pdf>. Acesso em: 27 out. 2014.

CANOTILHO, J. J. Gomes. Direito constitucional e teoria da constituição. 7. ed. Coimbra: Coimbra, 2003.

25 CANOTILHO, J. J. Gomes. Direito constitucional e teoria da constituição. 7. ed. Coimbra: Coimbra, 2003. p. 1448. 
GALVÃO, Ciro di Benatti. O dever jurídico de motivação administrativa: parâmetro objetivo para a racionalidade decisória dos atos administrativos restritivos de direito. Rio de Janeiro: Lumen Juris, 2013.

HESSE, Konrad. A força normativa da Constituição. Tradução de Gilmar Ferreira Mendes. Porto Alegre: S. A. Fabris, 2002.

HIRSCHL, Ran. O novo constitucionalismo e a judicialização da política pura no mundo. Revista de Direito Administrativo, n. 251, maio/ago. 2009.

KMIEC, Keenan D. The Origin and Current Meanings of Judicial Activism. California Law Review, v. 92, issue 5, p. 1441-1478, 2004.

MARINONI, Luiz Guilherme. A jurisdição no Estado constitucional. Disponível em: < http://www.marinoni. adv.br/artigos.php>. Acesso em: 06 out. 2014.

MEDINA, Paulo Roberto de Gouvêa. Teoria geral do processo. Belo Horizonte: Del Rey, 2012.

NOVAIS, Jorge Reis. Os princípios constitucionais estruturantes da República Portuguesa. Coimbra: Coimbra, 2011.

NOVAIS, Jorge Reis. Separação de poderes e limites da competência legislativa da Assembleia da República. Lisboa: Lex, 1997

OLIVEIRA, Marcelo Andrade Cattoni de. Teoria da Constituição. Belo Horizonte: Initia Via, 2012

PELEJA JÚNIOR, Antônio Veloso. As sentenças aditivas na jurisdição constitucional. In: FUX, Luiz (Coord.). Processo Constitucional. Rio de Janeiro: Forense, 2013.

PIÇARRA, Nuno. A Separação dos Poderes como doutrina e princípio constitucional: um contributo ara o estudo das suas origens e evolução. Coimbra: Coimbra, 1989.

SANTAROSA, Humberto. Jurisdição Criativa e a motivação das decisões judiciais como seu aspecto legitimador. In: FUX, Luiz (Coord.). Processo Constitucional. Rio de Janeiro: Forense, 2013.

SCHMIDT-ASSMANN, Eberhard. La teoria general del derecho administrativo como sistema: objeto y fundamentos de la construcción sistemática. Madri: INAP, 2003.

STRECK, Lênio Luiz. Hermenêutica e princípios da interpretação constitucional. In: CANOTILHO. J. J.

Gomes et al. (Coord.). Comentários à Constituição do Brasil. São Paulo: Saraiva; Almedina, 2013.

STRECK, Lênio Luiz. Jurisdição Constitucional e Hermenêutica: perspectivas e possibilidades de concretização dos direitos fundamentais sociais no Brasil. Novos Estudos Jurídicos, v. 8, n. 2, p. 257-301, 2003.

STRECK, Lênio Luiz; OLIVEIRA, Fábio de. Comentário ao art. 2. In: CANOTILHO, J. J. Gomes et al. (Coord.). Comentários à Constituição do Brasil. São Paulo: Saraiva; Almedina, 2013.

YOUNG, Ernest A. Judicial activism and conservative politics. University of Colorado Law Review, v. 73, n. 4. p. 1139-1216, 2002. 
Para publicar na revista Brasileira de Políticas Públicas, acesse o endereço eletrônico www.rbpp.uniceub.br

Observe as normas de publicação, para facilitar e agilizar o trabalho de edição. 